\title{
Widening the clinical spectrum of Pitt-Rogers-Danks/Wolf-Hirschhorn syndromes
}

\author{
Juliana F. Mazzeu ${ }^{1}$, Ana Cristina Krepischi-Santos ${ }^{1}$, Carla Rosenberg ${ }^{1}$,Charles M. Lourenço ${ }^{2}$, \\ Karina Lezirovitz ${ }^{1}$, Karoly Szuhai ${ }^{3}$, Lúcia R. Martelli ${ }^{2}$ and Angela M. Vianna-Morgante ${ }^{1}$ \\ ${ }^{I}$ Departamento de Genética e Biologia Evolutiva, Instituto de Biociências, Universidade de São Paulo, \\ São Paulo, SP, Brazil. \\ ${ }^{2}$ Departamento de Genética, Faculdade de Medicina de Ribeirão Preto, Universidade de São Paulo, \\ Ribeirão Preto, SP, Brazil. \\ ${ }^{3}$ Department of Molecular Cell Biology, Leiden University Medical Center, Leiden, The Netherlands.
}

\begin{abstract}
Chromosomal rearrangements involving partial deletion of the short arm of chromosome 4 and partial duplication of the short arm of chromosome 8 have been described both in Pitt-Rogers-Danks syndrome (PRDS) and WolfHirschhorn syndrome (WHS), the former being considered a milder phenotype of the latter. We describe a patient with partial deletion of chromosome 4 and partial duplication of chromosome 8 documented by array-comparative genomic hybridization (Array-CGH). In addition to the typical features of PRDS, the patient exhibited some clinical signs (genital hypoplasia, radioulnar synostosis and mesomelic limb shortness) infrequently, or never previously, reported in PRDS. These findings broaden the spectrum of anomalies generally associated with these syndromes.
\end{abstract}

Key words: Pitt-Rogers-Danks syndrome, Robinow syndrome, translocation t(4;8), Wolf-Hirschhorn syndrome.

Received: August 9, 2006; Accepted: December 20, 2006.

Chromosome rearrangements involving partial deletion of the short arm of chromosome 4 and partial duplication of the short arm of chromosome 8 have been described in patients with Pitt-Rogers-Danks syndrome (PRDS; MIM 262350; Clemens et al., 1996), which has been considered to be part of the phenotypic variability of Wolf-Hirschhorn syndrome (WHS; MIM 194190; Zollino et al., 1996). The affected individuals present with intrauterine growth retardation, severe mental delay, short stature, microcephaly, large forehead, prominent eyes, hypertelorism/telecanthus, beaked nose, large mouth, maxillary hypoplasia and joint hyperextensibility (Clemens et al., 1996; Linderman-Kusse et al., 1996; Pitt et al., 1984).

We describe a patient carrying the chromosomal imbalance typically found in PRDS but also presenting with unusual clinical manifestations. This observation widens the clinical spectrum classically associated with PRDS.

The patient (Figure 1a) was referred because of psychomotor retardation. She was born at term by $\mathrm{C}$-section delivery. Birth weight was $1700 \mathrm{~g}\left(<3^{\text {rd }}\right.$ centile $)$, length

Send correspondence to Angela M. Vianna-Morgante. Departamento de Genética e Biologia Evolutiva, Instituto de Biociências, Universidade de São Paulo, Caixa Postal 11461, 05422-970 São Paulo, SP, Brazil. E-mail: avmorgan @ib.usp.br.
$41 \mathrm{~cm}\left(<3^{\text {rd }}\right.$ centile) and head circumference (OFC) $31 \mathrm{~cm}$ $\left(<2^{\text {nd }}\right.$ centile $)$. Prenatal ultrasonography had shown intrauterine growth retardation. She presented feeding difficulties, and developmental milestones were delayed. Clinical evaluation at 3 years of age showed short stature $(76 \mathrm{~cm}$, $<3^{\text {rd }}$ centile), low weight $\left(7610 \mathrm{~g},<3^{\text {rd }}\right.$ centile), microcephaly (OFC $42 \mathrm{~cm},<2^{\text {nd }}$ centile), frontal bossing and balding, midface hypoplasia, long eyelashes, epicanthal folds, prominent eyes, impression of hypertelorism, long palpebral fissures, depressed nasal bridge, short philtrum, triangular mouth, thin upper lip, highly arched palate, dental malocclusion, short neck and pectus excavatum. Labia majora and minora were hypoplastic. Upper limbs had mesomelic shortness with radioulnar synostosis (Figure 1b), and limited elbow suppination. Hands were short with brachydactyly and $5^{\text {th }}$ finger clinodactyly. Interatrial communication and gastroesophageal reflux were surgically repaired. Radiographs showed delayed bone age (chronological age: 1 year; bone age: 2 months). She had frequent seizures. Karyotype had been reported to be normal.

Array-comparative genomic hybridization (array$\mathrm{CGH}$ ) analysis was performed using DNA from peripheral blood lymphocytes (Rosenberg et al., 2006). The slides containing triplicates of $\sim 3,500$ large insert clones spaced at $\sim 1.0 \mathrm{Mb}$ density over the full genome were produced at 


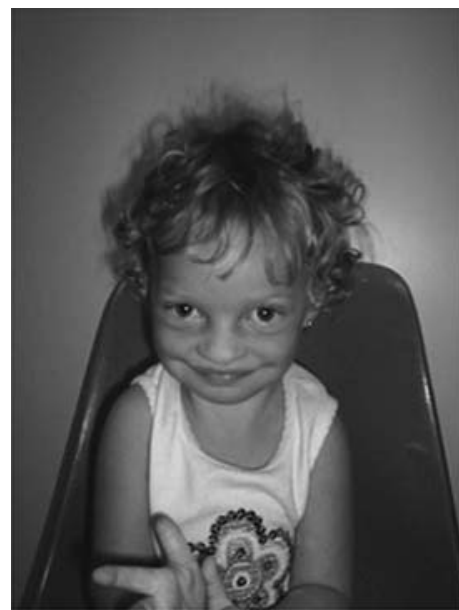

(a)

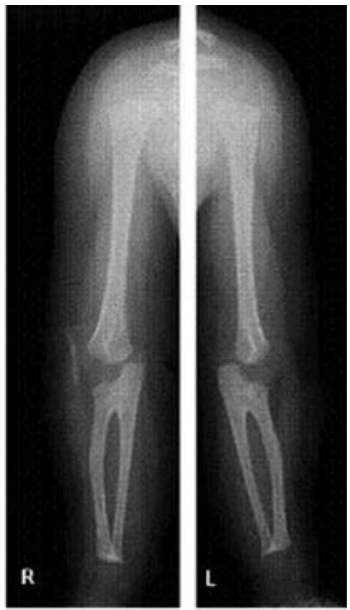

(b)
Figure 1 - Deletion $4 p$ and duplication $8 p$ revealed by array-CGH (A and C), and confirmed by FISH (B and D): The deleted (A) and duplicated (B) clones are shown in the array profiles and corresponding chromosome idiograms. After FISH a derivative chromosome 4 was identified, showing deletion of clone GS-36-21 (B), and addition of clone GS-580-L5 (D). Arrows point to der (4).

the Leiden University Medical Center. Information regarding the full set of clones is available at the Wellcome Trust Sanger Institute mapping database site, Ensembl. Copy number alterations detected by array-CGH were validated by fluorescence in situ hybridization (FISH) (Rosenberg et al. 1994). The parents were tested for the presence of alterations confirmed in the patient.

In order to determine the parental origin of the chromosome rearrangement, we genotyped markers D4S412 and D4S2935 mapped to chromosome 4p and D8S264 and D8S277 mapped to chromosome 8p (ABI PRISM Linkage Mapping Set v.2.5-MD10 kit, Applied Biosystems). For DNA amplification we used a final volume of $10 \mu \mathrm{L}$ containing 50-100 ng of genomic DNA, $0.5 \mu \mathrm{L}$ of primers marked with fluorochromes $(5 \mu \mathrm{M})$ and $6 \mu \mathrm{L}$ of True Allele Premix. The amplified products and the size standard (MegaBace TM "ET550-R Size Standard") were run on a MegaBace TM1000 sequencer (Amersham Biosciences) and analyzed using the Genetic Profiler v.1.5 software.

This study was approved by the National Research Ethics Committee (CONEP), and informed consent was obtained from the legal guardian of the patient.

Array-CGH analysis (Figure 2A and C) demonstrated a terminal deletion of a segment $(\sim 8 \mathrm{Mb}$ to $10 \mathrm{Mb})$ distal to clone RP11-117J13 (4p16.1), and a terminal duplication encompassing a segment $(\sim 6.5-\mathrm{Mb}$ to $8 \mathrm{Mb})$ of the short arm of chromosome 8 distal to clone CTD-2629I16 (8p23.1). These alterations were confirmed by FISH of subtelomeric probes of chromosomes 4 (GS-36-21) and 8 (GS-580-L5) to metaphase chromosomes (Figure 2B and D), FISH of the same probes hybridized to the chromo- somes of the parents did not reveal any alteration of these segments.

Microsatellite analyses showed a single allele of paternal origin at the loci mapped to chromosome 4 (D4S412 and D4S2935) and a more amplified maternal allele at loci mapped to chromosome 8 (D8S264 and D8S277), thus pointing to the maternal origin of the chromosomal imbalance (data not shown). Indeed, whenever investigated, unbalanced $\mathrm{t}(4 ; 8)$ translocations have been proven to be of maternal origin (Zollino et al., 2004).

The rearranged derivative chromosome 4 [der(4)] in our patient resulted from a de novo translocation between chromosomes 4 and 8 . These translocations are relatively frequent, and appear to be mediated by clusters of olfactory receptor genes with high sequence identity on the short arms of chromosomes 4 and 8 (Giglio et al., 2001; Giglio et al., 2002). In our patient, a $\sim 6.5-8 \mathrm{Mb}$ segment from chromosome 8 was translocated to chromosome 4 . The breakpoint on chromosome 4 mapped close to the distal gene cluster, and the der(4) had a deletion encompassing $\sim 8-10 \mathrm{Mb}$ of the short arm. This is considered a large deletion including the Wolf- Hirschhorn critical region (Zollino et al., 2004).

The der (4) in our patient has been previously associated with PRDS (Clemens et al., 1996). Our patient presented the clinical findings most frequently associated with this syndrome, but some of her clinical signs, namely genital hypoplasia, radioulnar synostosis and mesomelic limb shortness, were rarely or never reported in this condition. The only PRDS patient described previously with radioulnar synostosis had an atypical phenotype without intrauterine growth retardation, short stature, microcephaly or seizures, important signs for the diagnosis of the syndrome. This patient did not carry the deletion of the WHS critical region (Zollino et al., 1996). Genital hypoplasia was described in a single patient by Donnai et al. (1986), but the mesomelic shortness observed in our patient has not been previously reported in PRDS syndrome. Indeed, short stature, mesomelic limb shortness and genital hypoplasia are clinical signs found in more than $70 \%$ of Robinow syndrome patients (Butler and Wadlington, 1987; Mazzeu et al., 2007). However, the combination of symptoms in our patient is not typical of Robinow syndrome patients, particularly regarding craniofacial features. The observation of the characteristic chromosomal imbalance allowed us to confirm diagnosis of PRDS.

Pitt-Rogers-Danks syndrome is considered to be part of the clinical spectrum of Wolf-Hirschhorn syndrome since the deleted segment in chromosome 4 is similar in both syndromes (Bergmann et al., 2005; Wright et al., 1998; Wieczorek et al., 2000; Zollino et al., 1996). However, unbalanced translocations involving chromosomes 4 and 8 like the one described here are less frequent in WHS than in PRDS patients, the latter presenting a less severe phenotype, which sometimes does not include midline de- 
A
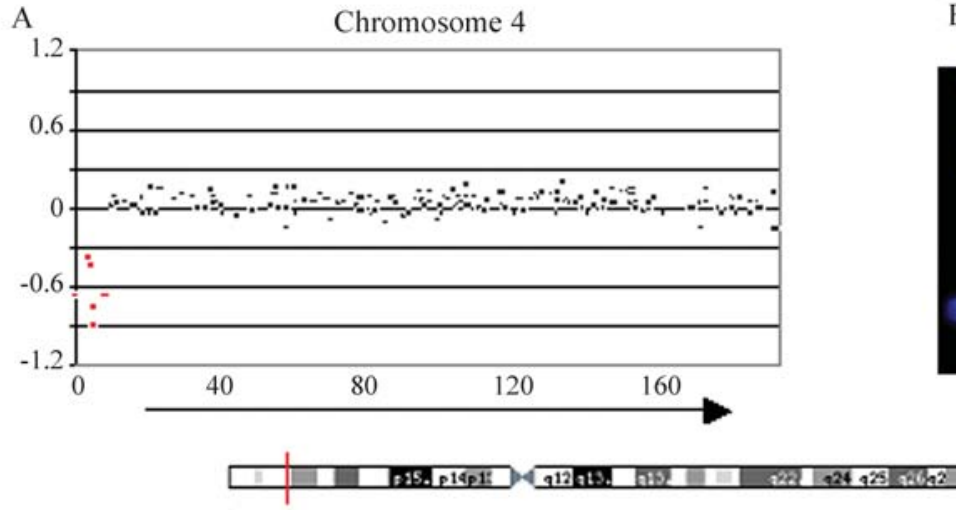

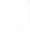
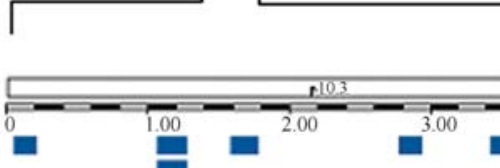

- Nondeleted clone

C

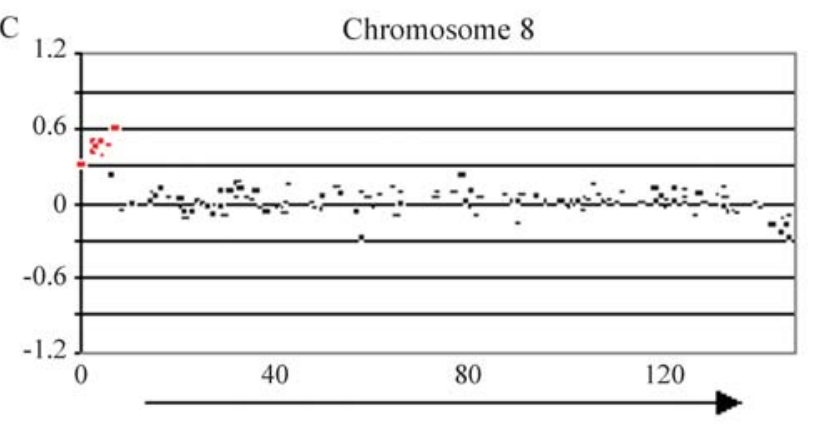

- Deletec clones

B

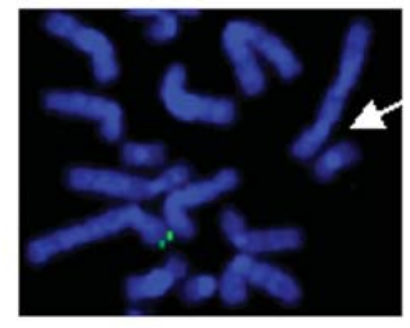

132 10221004 
Butler MG and Wadlington WB (1987) Robinow syndrome: Report of two patients and review of literature. Clin Genet 31:77-85

Clemens M, Martsolf JT, Rogers JG, Mowery-Rushton P, Surti U and McPherson E (1996) Pitt-Rogers-Danks syndrome: The result of a $4 p$ microdeletion. Am J Med Genet 66:95-100.

Donnai D (1986) Brief clinical report: A further patient with the Pitt-Rogers-Danks syndrome of mental retardation, unusual face and intrauterine grow retardation. Am J Med Genet 24 29-32.

Giglio S, Browman KW, Matsumoto N, Calvari V, Gimelli G, Neuwman T, Ohashi N, et al. (2001) Olfactory receptorgene clusters, genomic-inversion polymorphisms and common chromosome rearrangements. Am J Hum Genet 68:874-883.

Giglio S, Calvari V, Gregato G, Gimelli G, Camani S, Giorda R, Ragusa A, et al. (2002) Heterozygous submicroscopic inversions involving olfactory receptor-gene clusters mediate the recurrent $\mathrm{t}(4 ; 8)(\mathrm{p} 16 ; \mathrm{p} 23)$ translocation. Am J Hum Genet 71:276-285.

Linderman-Kusse MC, Van Haeringen A, Hoorweg-Nijman JJ and Brunner HG (1996) Cytogenetic abnormalities in two new patients with Pitt-Rogers-Danks phenotype. Am J Med Genet 66:104-112.

Mazzeu JF, Pardono E, Vianna-Morgante AM, Richieri-Costa A, Kim CA, Brunoni D, Martelli L, et al. (2007) Clinical characterization of autosomal dominant and recessive variants of Robinow syndrome. Am J Med Genet 143:320-325.

Pitt DB, Rogers JG and Danks DM (1984) Mental retardation, unusual face, and intrauterine growth retardation: A new recessive syndrome? Am J Med Genet 19:307-13
Rosenberg C, Janson M, Nordeskjold M, Borresen AL and Vianna-Morgante AM (1994) Intragenic reorganization of RB1 in a complex $(4 ; 13)$ rearrangement demonstrated by FISH. Cytogenet Cell Genet 65:268-271

Rosenberg C, Knijnenburg J, Bakker E, Vianna-Morgante A, Sloos WC, Otto PA, Kriek M, et al. (2006) Array-CGH detection of micro rearrangements in mentally retarded individuals: Clinical significance of imbalances present both in affected children and normal parents. J Med Genet 43:180186

Wieczorek D, Krause M, Majewski F, Albrecht B, Meinecke P, Riess O and Gillessen-Kaesbach G (2000) Unexpected high frequency of de novo unbalanced translocations in patients with Wolf-Hirschhorn syndrome (WHS). J Med Genet 37:798-804

Wright TJ, Clemens M, Quarrel O and Altherr MR (1998) WolfHirschhorn and Pitt-Rogers-Danks syndromes caused by overlapping 4p deletions. Am J Med Gen 75:345-350.

Zollino M, Bova R and Neri G (1996) From Pitt-Rogers-Danks syndrome to Wolf-Hirschhorn syndrome and back? Am J Med Genet 68:113-115.

Zollino M, Lecce R, Selicorni A, Murdolo M, Mancuso I, Marangi G, Zampino G, et al. (2004) A double cryptic chromosome imbalance is an important factor to explain phenotypic variability in Wolf-Hirschhorn syndrome. Eur J Hum Genet 12:797-804

\section{Internet Resources}

Ensembl (http://www.ensembl.org/)

Online Medelian Inheritance in Man (OMIM), http://www.ncbi. nlm.nih.gov/omim. 